\title{
Application of Direct Integration Methods in the solution of a nonlinear beam problem
}

\section{Aplicação de Métodos de Integração Direta na solução de um problema não linear de viga}

Raul Carreira Rufato

Universidade Federal de Uberlândia (UFU), Faculdade de Engenharia Mecânica (FEMEC), Uberlândia, MG, Brasil

https://orcid.org/0000-0001-9753-6159, raulc.rufato@hotmail.com Santos Alberto Enriquez-Remigio Universidade Federal de Uberlândia (UFU), Faculdade de Matemática (FAMAT), Uberlândia, MG, Brasil

https://orcid.org/0000-0002-5088-7311, santos.er@ufu.br Tobias Souza Morais Universidade Federal de Uberlândia (UFU), Faculdade de Engenharia Mecânica (FEMEC), Uberlândia, MG, Brasil https://orcid.org/0000-0001-6341-0881, tobias@ufu.br

\section{Article informations}

\section{How to cite this article}

RUFATO, Raul Carreira; ENRIQUEZ-REMIGIO, Santos Alberto; MORAIS, Tobias Souza. Application of Direct Integration Methods in the solution of a nonlinear beam problem. REMAT:

\section{Revista Eletrônica da} Matemática, Bento Gonçalves, RS, v. 7, n. 1, p. e3002, 8 jan. 2021. DOI: https://doi.org/10. 35819/remat2021v7i1id4277.

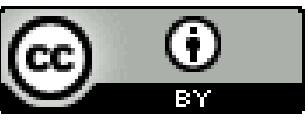

\section{Abstract}

This work applies different numerical methods involved in the solution of a nonlinear clamped beam problem. The methodology used in the discretization of the dynamic problem is based on the Finite Element Method (FEM), followed by mode superposition, where a localized nonlinearity is applied at the free end of the beam. The solution of the nonlinear problem is performed by five different integration methods. The solution code is implemented in FORTRAN language, validated with ANSYS and the dy-

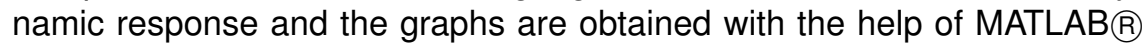
software. The work shows the convergence of the implemented methods with various validation problems.

Submission: June 19, 2020.

Accept: September 4, 2020.

\section{Keywords}

Numerical Methods

Finite Element Method

Mode Superposition 
Palavras-chave

Métodos Numéricos

Método dos Elementos Finitos

Superposição Modal

\begin{abstract}
Resumo
Este trabalho aplica diferentes métodos numéricos envolvidos na solução de um problema de viga não linear engastada em uma de suas extremidades. A metodologia usada na discretização do problema dinâmico é baseada no Método dos Elementos Finitos (MEF), seguido pela superposição de modo, onde uma não linearidade localizada é aplicada na extremidade livre da viga. A solução do problema não linear é realizada por cinco diferentes métodos de integração. O código da solução é implementado na linguagem FORTRAN, validado com o ANSYS e a resposta dinâmica e os gráficos são obtidos com a ajuda do software MATLAB $B$. $O$ trabalho mostra a convergência dos métodos implementados para os vários problemas de validação.
\end{abstract}

\section{Introduction}

The analysis of dynamical systems in the time domain can be solved using different numerical solution methodologies of the differential equation involved in the problem. This work presents a validation and application of these different methods when submitted to a nonlinear dynamic problem. The nonlinear case is much more complex than the linear case, however it is widely applicable in numerous systems. As says Strogatz (2018): nonlinear systems are impossible to solve analytically and that is why numerical methods are needed to solve these kind of problems.

Systems of nonlinear equations are presented in several problems and solving them is one of the main purposes of applied mathematics. Then, considering the nonlinear problem and the associated solution method adopted, it is necessary to analyse different parameters, such as computational efficiency, methods with a rapid convergence to the desired solution, errors and initial conditions effect in the response. In recent years, large scale nonlinear equations have been attracting more attention from researchers. Yuan (2011) shows recent developments in numerical methods for the solution of nonlinear equations, particularly on Newton's method, quasi-Newton method, Gauss-Newton method, Levenberg-Marquardt method and trust region method. It also shows some theoretical results about local convergence. Realizing the importance of a more in-depth study of numerical methods for systems of nonlinear equations, Remani (2013) presented an extremely detailed study with examples of implementation in MATLAB, comparing methods such as centered differences and Newton method for systems with a high number of equations. This continuous development of nonlinearities in many areas and examples of applications with further study can be found in Strogatz (2018). 
The analysis of numerical methods in the solution of problems of nonlinear structures was already present in some works decades ago. It is noted Regina Célia (1983), which demonstrates the main numerical characteristics of the algorithms of direct integration in nonlinear dynamics of structures using the Finite Element Method. Additionally, this work includes the analysis of the Newmark Method and Centered Differences, treating nonlinear parts as pseudo-forces and verifying the dynamic balance together with the stability of the algorithms, based on the concept of energy conservation. It is evident the evolution in the solution of this type of nonlinear problem with the advancement of computing in this century. With the necessity to evaluate the performance of the algorithms, Chang (2004) studied the performance of the Newmark method in nonlinear problems. This also emphasizes the need to study the stability of these numerical integration methods in nonlinear structures problems. In Rezalee-Pajand and Karimi-Rad (2017), a new accurate predictor-corrector time integration method is proposed, which is shown superior to the centered differences method, and has second-order accuracy for structures with and without damping. Moreover, it is observed the importance of studying these methods in nonlinear beam problems, which are very common and can be the basic model of several complex systems. Looking at what was done in Tsai (2005), a study which compares numerical solutions for nonlinear beam problems (solutions for nonlinear 4-th order ordinary differential equations with nonlinear boundary conditions), and several methods to finally classify the best ones. In Khan and Kaneez (2017) also a new numerical method for nonlinear vibrational analysis of Euler-Bernoulli beams is presented, showing the importance of studying this subject.

This work presents the whole methodology involved and necessary in the problem for the analysis of these different numerical methods.

Section 2 presents the methodology of this work. Section 3 shows the development of all physical and numerical models used in this work. Starting at 3.1 for the beam discretization and modal analysis compared to the ANSYS software. Section 3.2 presents the numerical methods implemented to solve the system of differential equations. Then, at Section 3.3, the solution of these methods for a linear problem is presented in comparison with the commercial Finite Element software. Finally, Section 3.4 shows the solution for two nonlinear systems using the physical model and the numerical methods implemented. All problems in these sections have the same physical beam model. 


\section{Methodology}

The developed model in this work could represent a bridge, a wing of an aircraft or even the suspension of a vehicle (changing only the boundary conditions applied). Firstly, the linear case is developed and validated. Then, based on this model, a localized nonlinearity is introduced in order to show the results of the implemented methods. The numerical verification are performed varying the temporal and spatial discretization, using Manufactured Solutions, such results not shown here. All the methods and functions used for solving the problems were implemented in FORTRAN language (https://fortran-lang.org). The validation of the physical and numerical model was based on comparisons with ANSYS $\AA$ software using a beam element type.

\section{The nonlinear problem for time analysis}

The nonlinear problems presented here are based on a cantilever beam with a force imposed at the free, which turns the modelling into a nonlinear system. Two problems will be analysed.

The analyzed beam is made of steel (having the Young's Module $E=2.068 .10^{11} \frac{\mathrm{N}}{\mathrm{m}^{2}}$, and the Poisson's dimensionless coefficient $\nu=0.3$ ) with a constant cross section of $0.01 \mathrm{~m} \times 0.01 \mathrm{~m}$ and length of $1 \mathrm{~m}$.

The mathematical physical modelling of the dynamical system is given by the following secondorder ordinary differential Eq. (1):

$$
[M][\ddot{x}(t)]+[C][\dot{x}(t)]+[K][x(t)]=f(t)
$$

where $[M]$ represents the mass matrix of the system, $[K]$ the stiffness matrix, $[C]$ the damping matrix, $x(t)$ the displacements vector and $f(t)$ the external force applied (which can be linear or not). $\dot{x}(t)$ represents derivative of the response with respect to the time. The Euler-Bernouli beam, with two nodes per elements and two degrees of freedom per node, one of translation and one of rotation, was considered. The Finite Element Method (FEM) composed by $1 \mathrm{D}$ beam formulation is used to

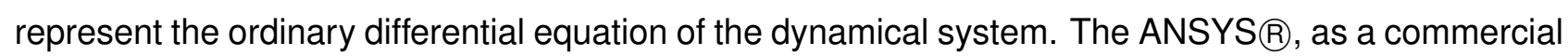
and validated Finite Element Software, is used as baseline to validate the implemented FEM and numerical integrations procedures. 


\subsection{Beam discretization and modal analysis}

Firstly, the mass and stiffness matrices of a cantilever beam were obtained by finite element modelling (HUTTON, 2004) and validated. For this, a modal analysis of the physical model was performed considering the beam divided in 20 elements. This analysis consists on the determination of the eigenvalues of the system dynamical matrix $\left([D]=[M]^{-1}[K]\right)$ and, the calculation theirs the natural frequencies. The results of this process are compared with those obtained by the ANSYS $\mathbb{B}$ Software and presented in Table 1 .

Table 1 - Comparison of natural frequencies obtained with the model.

\begin{tabular}{|c|c|c|}
\hline Physical Model $(\mathrm{Hz})$ & ANSYS $\AA(\mathrm{Hz})$ & Difference \% \\
\hline \hline 8.305 & 8.167 & 1.690 \\
\hline 51.972 & 51.230 & 1.448 \\
\hline 145.638 & 143.730 & 1.327 \\
\hline 286.082 & 282.570 & 1.243 \\
\hline 474.777 & 469.170 & 1.196 \\
\hline 712.670 & 704.78 & 1.119 \\
\hline
\end{tabular}

Source: Authors' elaboration (2020).

It is possible to observe that the differences presented in the table are bellow $1.7 \%$, which indicates that the physical model of the problem is representative. The slightly different results must be due to the elementary matrices used in each simulation and even the numerical method used in the inversion of the mass matrix.

\subsection{Numerical mathematical methods for solve the differential equation of motion}

With the mass and stiffness matrices, it is then possible to determine the numerical solution of the differential Eq. (1) by different numerical methodologies (BATHE, 2014). However, before the differential equation is solved, a modal reduction is performed (BORINO; MUSCOLINO, 1986) using the two modes with lower natural frequencies generated by the FEM code. Avoiding higher frequency mode shapes, a greater time step can be adopted, thus improving the stability of the numerical methods implemented.

The numerical methods chosen to solve the differential Eq. (1) are the direct integration methods. Consequently, five different types were implemented: linear Newmark Method, Nonlinear Newmark Method, Houbolt Method, Bathe Method and Central Difference Method (BATHE, 2014). 
According to Eq. (1), it will be presented each equation used for each method in its implementation as well as described in (BATHE, 2014).

1. The Central Difference Method. Known as an explicit method because it uses the time equilibrium conditions $t$. Starting the initial conditions, selecting the temporal step and applying Eq. (2), there is still a solution need for a linear system.

$$
\left(\frac{1}{\Delta t^{2}}+\frac{1}{2 \Delta t} C\right) x^{t+\Delta t}=f^{t}-\left(K-\frac{2}{\Delta t^{2}} M\right) x^{t}-\left(\frac{1}{\Delta t^{2}} M-\frac{1}{2 \Delta t} C\right) x^{t-\Delta t}
$$

2. The Houbolt Method. Already known as the implicit method, the implementation procedure resembles the Central Difference Method, but considering Eq. (3)

$$
\begin{gathered}
\left(\frac{2}{\Delta t^{2}} M+\frac{11}{6 \Delta t} C+K\right) x^{t+\Delta t}=f^{t+\Delta t}+\left(\frac{5}{\Delta t^{2}} M+\frac{3}{\Delta t} C\right) x^{t} \\
-\left(\frac{4}{\Delta t^{2}} M+\frac{3}{2 \Delta t} C\right) x^{t-\Delta t}+\left(\frac{1}{\Delta t^{2}} M+\frac{1}{3 \Delta t} C\right) x^{t-2 \Delta t}
\end{gathered}
$$

3. The Linear Newmark Method. It is also an implicit method, although it respects Eq. (4)

$$
\left(\frac{4}{\Delta t^{2}} M+\frac{2}{\Delta t} C+K\right) x^{t+\Delta t}=f^{t+\Delta t}-M\left(\frac{4}{\Delta t^{2}} x^{t}+\frac{4}{\Delta t} \dot{x}^{t}+\ddot{x}^{t}\right)+C\left(\frac{2}{\Delta t} x^{t}+\dot{x}^{t}\right)
$$

4. The Bathe Method. It uses two sub-steps for each time integration. In the first sub-step the Newmark Method is used and in the second sub-step, the 3-point Euler backward method is used. The initial conditions must be chosen as in the previous methods and it is also an implicit method of integration (Eq. (5), (6), (7), (8)).

$$
\begin{aligned}
\left(\frac{16}{\Delta t^{2}} M+\frac{4}{\Delta t} C+K\right) x^{t+\frac{\Delta t}{2}}= & \hat{f}^{t+\frac{\Delta t}{2}} \\
\hat{f}^{t+\frac{\Delta t}{2}}= & f^{t+\frac{\Delta t}{2}}+M\left(\frac{16}{\Delta t^{2}} x^{t}+\frac{8}{\Delta t} \dot{x}^{t}+\ddot{x}^{t}\right)+C\left(\frac{4}{\Delta t} x^{t}+\dot{x}^{t}\right) \\
\left(\frac{9}{\Delta t^{2}} M+\frac{3}{\Delta t} C+K\right) x^{t+\Delta t}= & \hat{f}^{t+\Delta t} \\
\hat{f}^{t+\Delta t}= & f^{t+\Delta t}+M\left(\frac{12}{\Delta t^{2}} x^{t+\frac{\Delta t}{2}}-\frac{3}{\Delta t^{2}} x^{t}+\frac{4}{\Delta t} \dot{x}^{t+\frac{\Delta t}{2}}-\frac{1}{\Delta t} \dot{x}^{t}\right)+ \\
& C\left(\frac{4}{\Delta t} x^{t+\frac{\Delta t}{2}}-\frac{1}{\Delta t} x^{t}\right)
\end{aligned}
$$

5. The Nonlinear Newmark Method. The difference between this and the Linear Newmark Method consists in the process of reducing the residue at each step-in time using the Newton method, being the residue (VIEIRA, 2004) described by Eq. (9).

$$
R^{t}=f^{t}-M \ddot{x}^{t}-C \dot{x}^{t}-K x^{t}
$$




\subsection{Linear problem validation}

The problem considered consists of a cantilever beam in which a constant external force $f=100 N$ is only applied at time $t=0$.

In order to compare the results presented by the methods implemented with those of the ANSYS $\AA$ software, the ANSYS Mechanical APDL was used considering the first two structural modes (as well as the implemented model). The simulation time was $1 s$ and the same time step was used for all methods $\left(10^{-4} s\right)$. The choice of this time step is the product of several numerical experiments, and for a time step less than or equal to $10^{-4}$ all methods guarantee the same solution

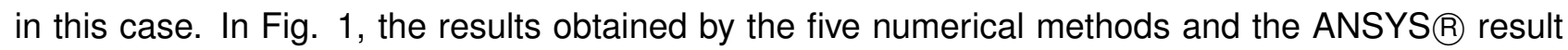
are shown.

Figure 1 - Linear problem validation.

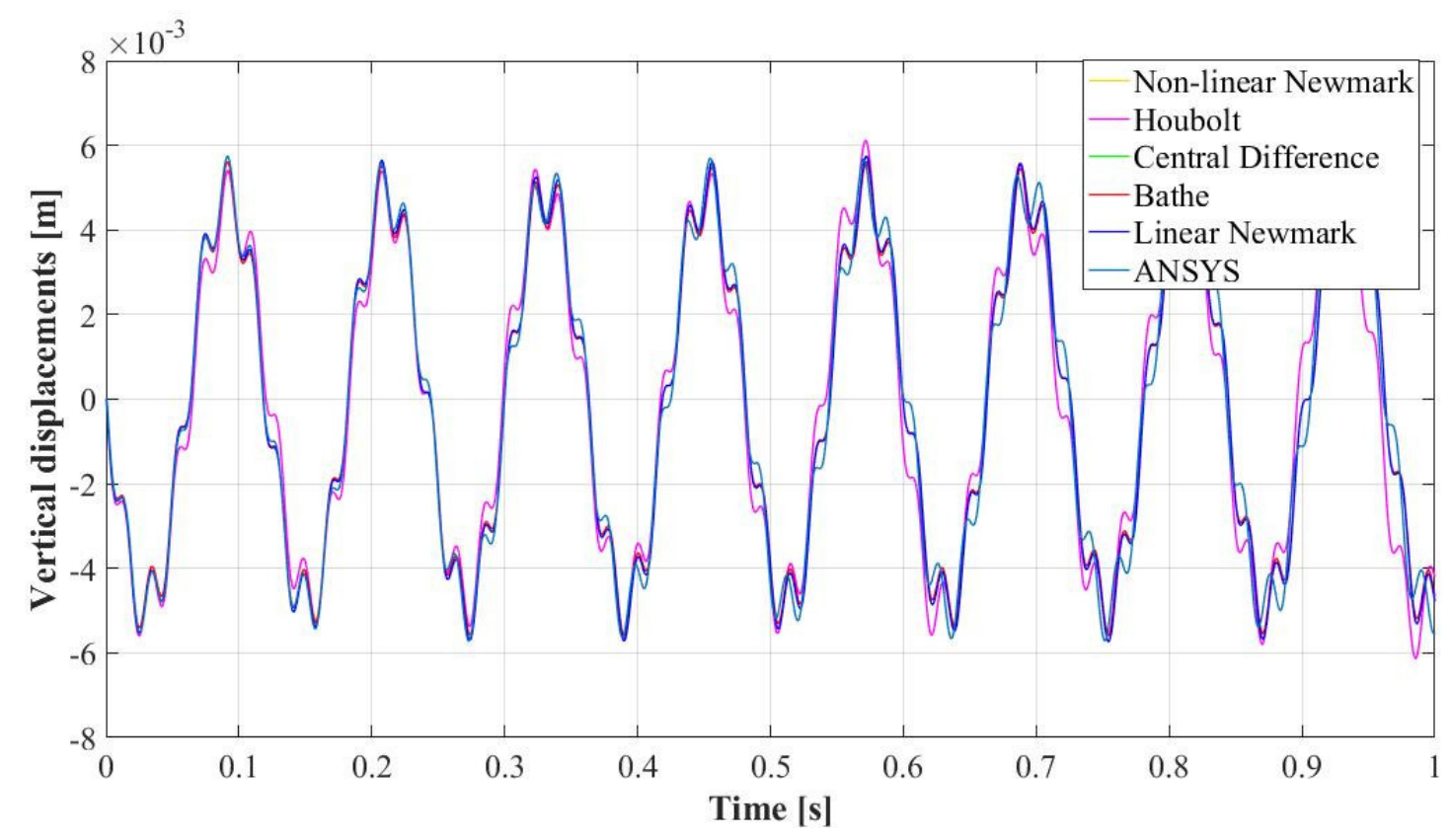

Source: Authors' elaboration (2020).

The results from Fig. 1, shows a proximity of the answers obtained by the implemented methods and the one obtained by the ANSYS $B$ software, which validates the mathematical and numerical methodology (for the linear dynamic system). 


\subsection{The nonlinear problem results}

After the computational verification of the implemented code, two nonlinear problems are simulated.

\subsubsection{Cantilever beam with a ball and a spring-damping system}

The nonlinear dynamical system modelled and shown in Fig. 2 consists of a cantilever beam with a ball on the top of it, moving at constant speed, and a spring-damping system at a distance $X_{0}=0.001 \mathrm{~m}$ from the end of the beam. In order to make the physical modelling of the system even more realistic, a damping model was implemented. This section uses the proportional damping model (ADHIKARI, 2000). It was considered only the first mode shape for modal reduction, in order to improve the graphic visualization of the solution.

Figure $2-$ Geometric setting of the cantilever beam with a moving ball and and a spring-damping system.

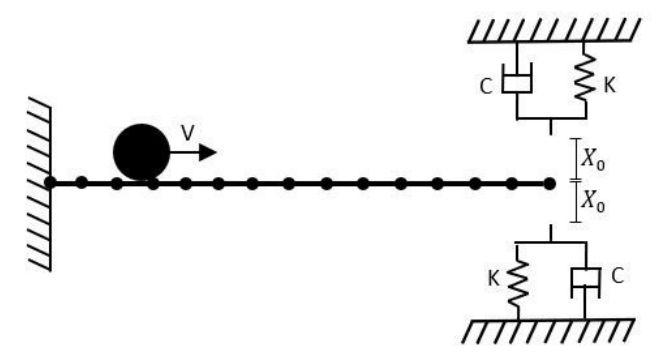

Source: Authors' elaboration (2020).

The nonlinear problem can have its nonlinearity modelled through $f=f_{1}+f_{2}$ given by:

$$
f_{1}=f_{k}+f_{c}= \begin{cases}-k\left(x_{k}(t)-X_{0}\right)^{2}-c \dot{x}_{k}(t), & \text { Se } x_{k} \geq X_{0} \\ k\left(x_{k}(t)-X_{0}\right)^{2}-c \dot{x}_{k}(t), & \text { Se } x_{k} \leq-X_{0}\end{cases}
$$

where $f_{k}(t)$ and $f_{c}(t)$ are the force due to a nonlinear spring and a linear damping respectively $(k=1000 \mathrm{~N} / \mathrm{m}, c=1 \mathrm{~N} / \mathrm{m} / \mathrm{s})$, implemented at a distance $X_{0}=0.001 \mathrm{~m}$ from the beam as shown in Fig. 2 and applied only in the last node. Whereas $f_{2}$ represents the force due to the displacement of the mass $(10 \mathrm{~kg})$ at constant speed. The movement of the ball (mass) was set to be continuously along the length of the beam and the loads transferred to the nodes at the same time. The equation of the ball movement is Eq. (11),

$$
S(t)=S_{0}+v t
$$

$S_{0}$ being the initial position of the ball and $v$ its constant speed, in this case it was considered $S_{0}=$ $0.1 \mathrm{~m}$ e $v=0.5 \mathrm{~m} / \mathrm{s}$. 
The simulation lasted $10 \mathrm{~s}$ and for each method implemented a different time step was used in order to guarantee convergence (Tab. 2). Fig. 3 shows the temporal response of the problem according to the displacement of the last node.

Table 2 - Step in time, $\Delta t$, used for each method in the problem of the cantilever beam with a moving ball and and a spring-damping system.

\begin{tabular}{|c|c|}
\hline & $\Delta t s$ \\
\hline \hline Nonlinear Newmark & $10^{-2}$ \\
\hline Houbolt & $10^{-6}$ \\
\hline Central Difference & $10^{-4}$ \\
\hline Bathe & $10^{-5}$ \\
\hline Linear Newmark & $10^{-2}$ \\
\hline
\end{tabular}

Source: Authors' elaboration (2020).

Figure 3 - Dynamics of the free end of a cantilever beam with a moving ball and a spring-damping system (Overlapping results, hence only one color).

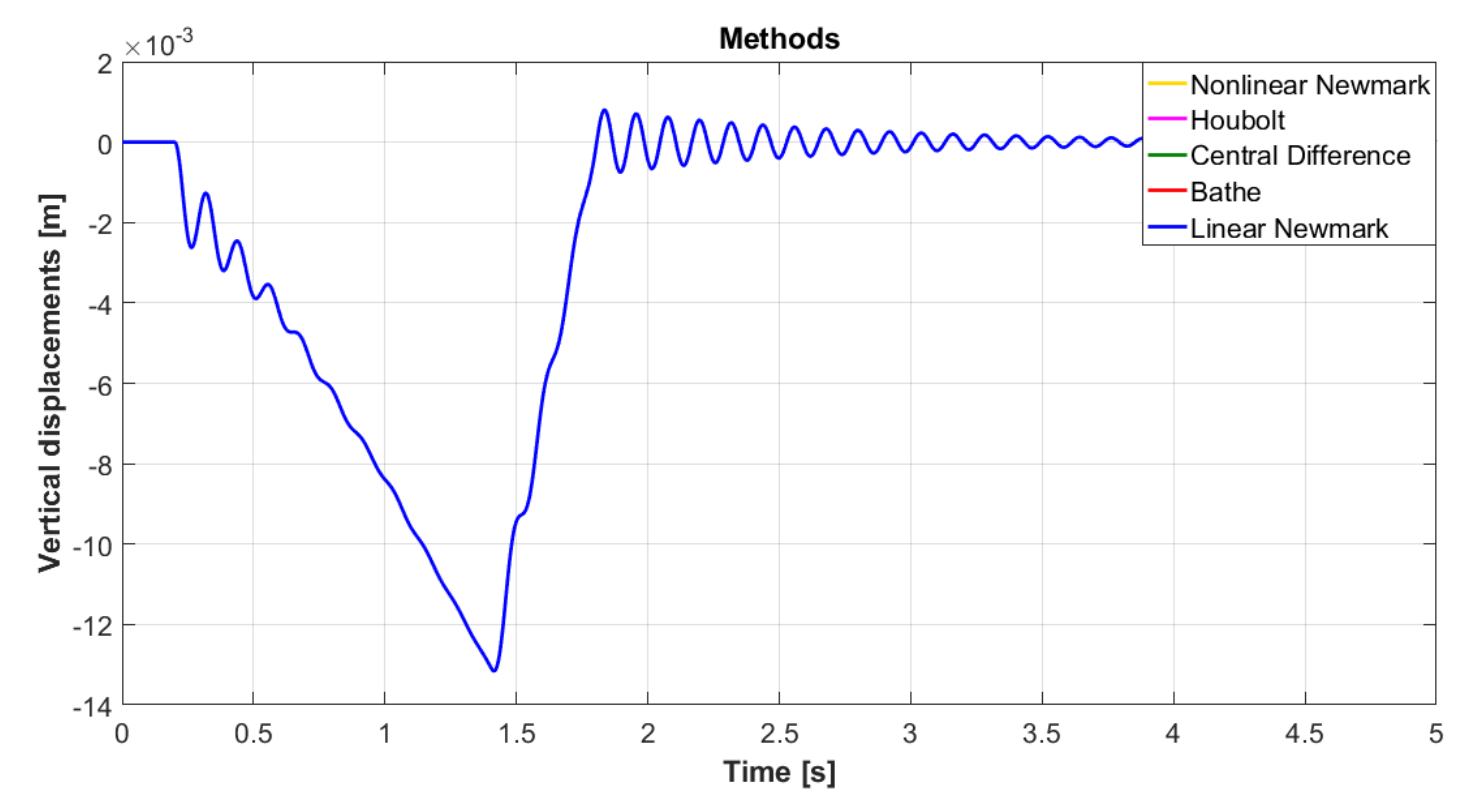

Source: Authors' elaboration (2020).

From Fig. 3 it is possible to verify that approximately at $1.4 s$ the ball reaches the end of the beam and falls, and, at this moment, the system dampens until it stops. It can also be verified that the beam touches the spring-damper system since the value of $X_{0}$ has exceeded at the bottom and at the top. 


\subsubsection{Cantilever beam with eletromagnetic actuators}

This problem consists of a cantilever beam with electromagnetic actuators located vertically at a predetermined (symmetrical) distance from its free end as shown in Fig. 4.

Figure $4-$ Geometric setting of the cantilever beam with electromagnetic actuators.

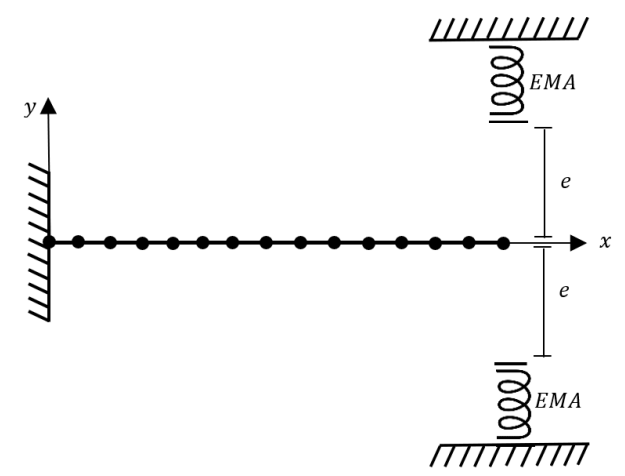

Source: Authors' elaboration (2020).

In this case, the structural damping effects have been suppressed in order to not dissipate energy from the system, thus improving the visualization of nonlinearities. It was considered only the first mode shape for modal reduction.

The beam characteristics are the same as in Section 3.4.1, where $e=0.1 \mathrm{~m}$ is the air gap value. In this problem, structural damping was still considered null. Electromagnetic actuators are modelled as nonlinear forces given by $f$ in Eq. (1) and defined by:

$$
f=F_{e m}+F_{a}
$$

where $F_{e m}$ represents the electromagnetic force induced by the actuators and $F_{a}$ the external force conditions applied to the system in order to further disturb its stability, consequently making nonlinear effects more noticeable. The expression for $F_{e m}$ is given by:

$$
F_{e m}=\frac{N^{2} \mu_{0} a g l^{2}}{2\left((e \pm x(t))+\frac{b+h+d-2 a}{\mu_{r}}\right)^{2}}
$$

in which coefficients $a, b, d, g$ and $h$ represents geometric characteristics of the actuators (See Fig. 5); $\mu_{0}$ represents the magnetic permeability of vacuum $\left(4 \pi 10^{-7} \mathrm{H} / \mathrm{m}\right) ; N$ the number of turns per actuator; $I$ the electric current passing through the actuators (in amps), $\mu_{r}$ is the relative magnetic permeability (dimensionless parameter, assumed constant in this case at the value of 740 , for low flow density) (BELHAQ et al., 2011). The values used are in Tab. 3. 
Table 3 - Parameters used for the geometric characteristics of the actuators.

\begin{tabular}{|c|c|}
\hline \hline$a$ & $10^{-3} m$ \\
\hline$b$ & $4 \times 10^{-2} m$ \\
\hline$d$ & $10^{-3} m$ \\
\hline$g$ & $2.1 \times 10^{-3} m$ \\
\hline$h$ & $3 \times 10^{-3} m$ \\
\hline$N$ & 180 \\
\hline$I$ & $0.2 A$ \\
\hline
\end{tabular}

Source: Authors' elaboration (2020).

Figure 5 - Characteristics of the electromagnetic actuators.

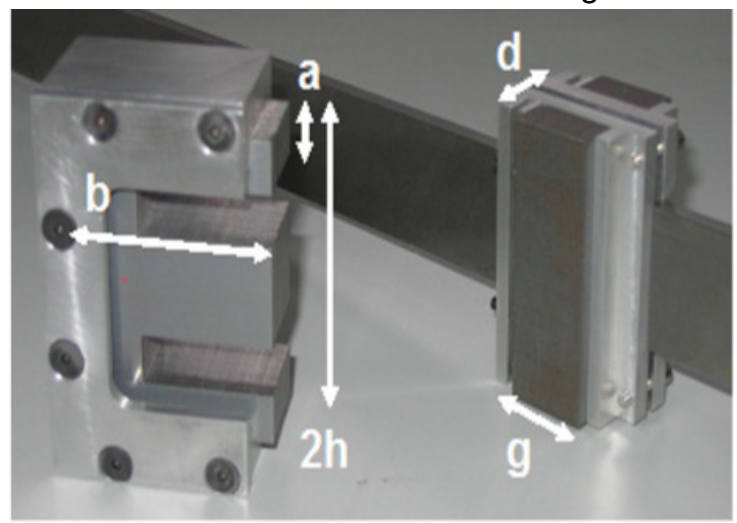

Source: BELHAQ et al., 2011.

The difference between this problem and the previous one is in the beam dynamics, whereas in the first problem after a certain time the position of the free end converges to an equilibrium position; the second problem oscillates between two well-defined equilibrium positions.

Two different types of conditions were applied to verify the behaviour of the system and the implemented methods. In the first one, $F_{a}$ was considered 0 and an ideal impulse was applied to the system at the value of $1.0 \mathrm{Ns}$ (which is mathematically equivalent to an initial velocity condition). Aiming to simplify the problem, only the results obtained on the last node of the mesh and their degree of freedom of translation were presented. Fig. 6 shows the transverse displacement relative to the time of this analysis position and Fig. 7 shows the system's phase diagram. 
Figure 6 - Time displacements for ideal impulse.
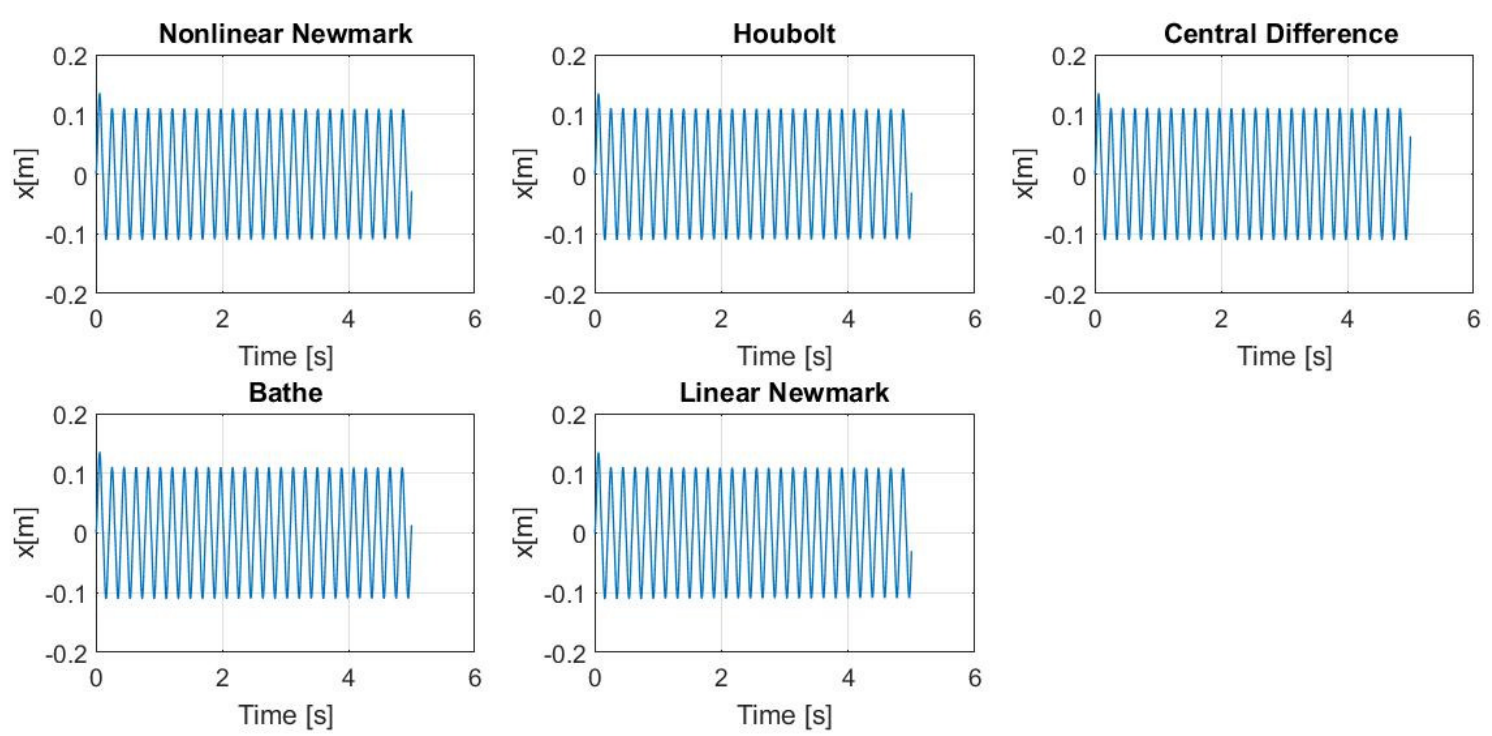

Source: Authors' elaboration (2020).

It is possible to observe that all methods oscillate around two equilibrium positions, starting with the positive side of the displacements (right area of the graphs), which is physically correct, since the applied impulse was in this direction.

In the second condition, $F_{a}=10 \sin (4.2, \pi, t)$ was considered and an ideal pulse was once again applied to the system at the value of $0.1 \mathrm{Ns}$. Fig. 8 shows the transverse displacement according to this analysis and Fig. 9 shows the system's phase diagram. 
Figure 7 - Phase diagram for ideal impulse.
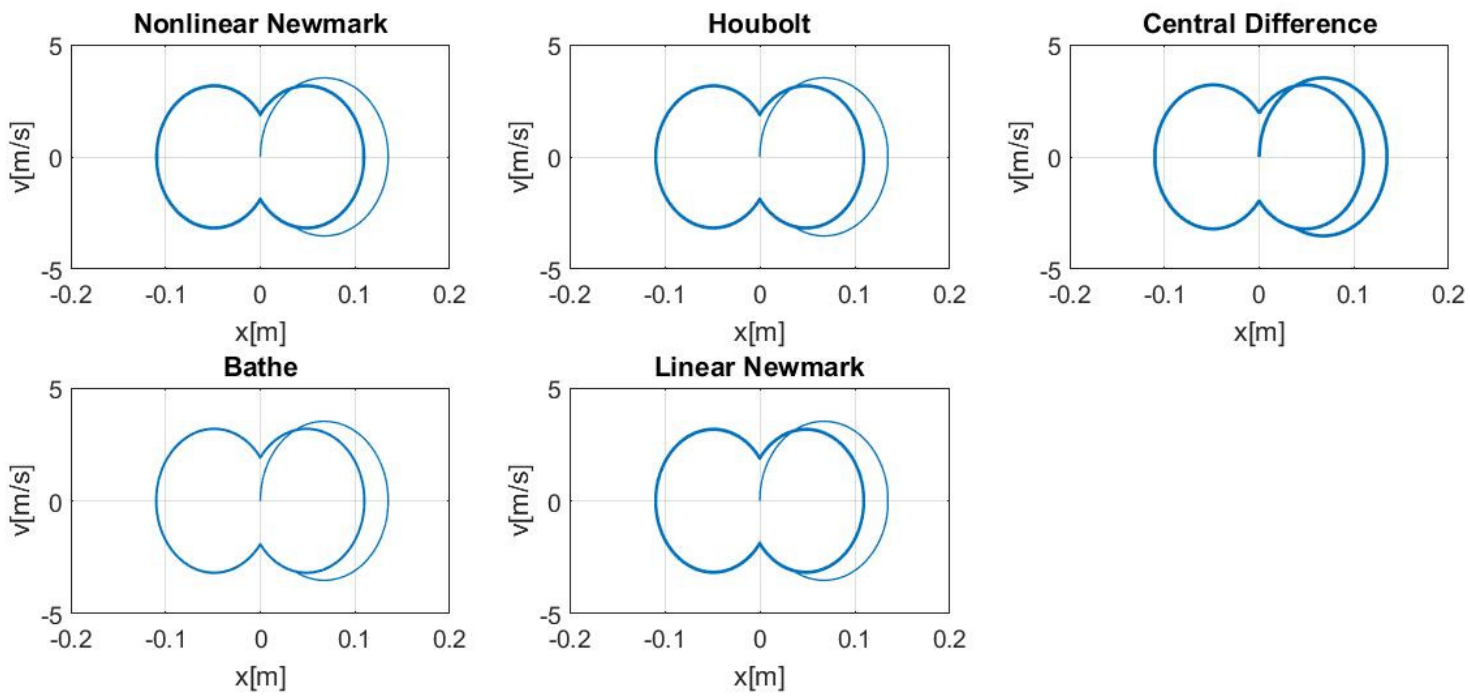

Source: Authors' elaboration (2020).

Figure 8 - Time displacements for ideal impulse and periodic force.
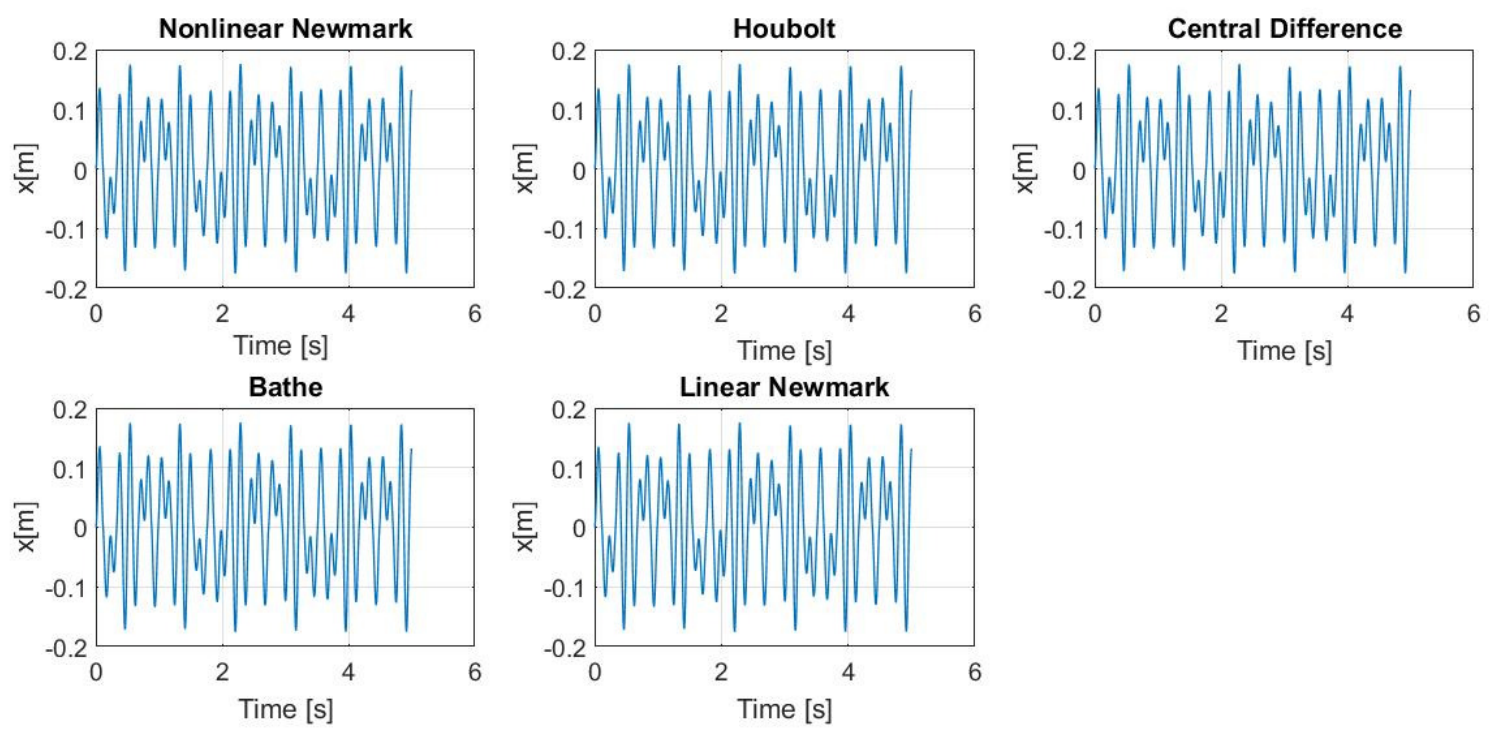

Source: Authors' elaboration (2020). 
Figure 9 - Phase diagram for ideal impulse and periodic force.
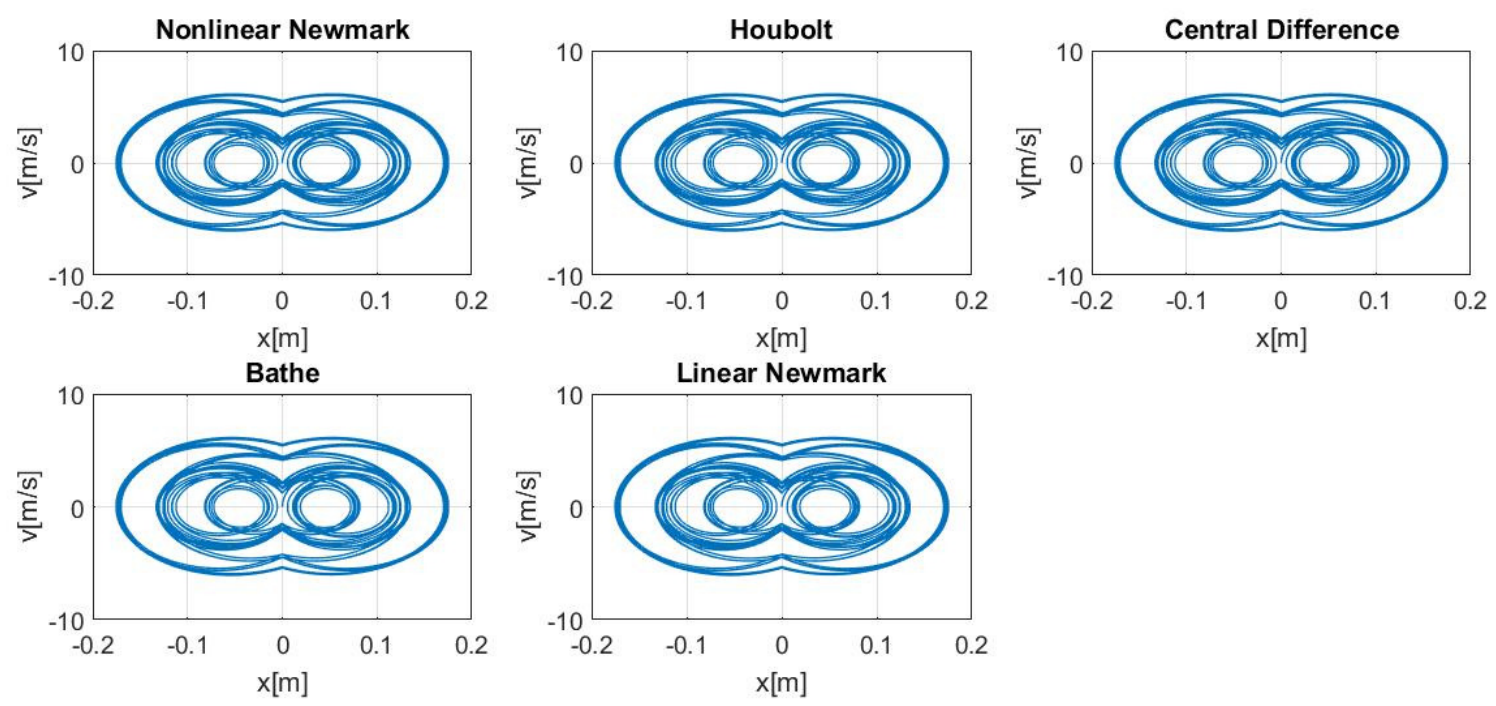

Source: Authors' elaboration (2020).

Comparing Fig. 6 and Fig. 8 of the transverse displacement of the end of the beam, we see that the periodic force $F_{a}$ influences the dynamics of this displacement, where the change from one equilibrium position to another is not linear.

The methods were executed for different time steps, $\Delta t$, and the results showed that all of the methods have the same qualitative behaviour: they oscillate around the two equilibrium positions and the Central Difference Method presents this behaviour at $\Delta t=10^{-3} \mathrm{~s}$, while others need smaller $\Delta t$. After $\Delta t=10^{-5} \mathrm{~s}$, all the methods report the expected behaviour.

\section{Conclusion}

The linear dynamic model was implemented and the procedure validated with the help of

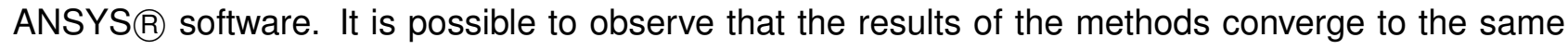
solution, therefore validating the implementation of the numerical methods.

After the validation of the linear problem, the methodology was used for two nonlinear problems. In the first problem, a cantilever beam with a ball and a spring-damping system was observed and the results obtained by the numerical methods were physically coherent, in which was necessary to use different time steps for each method. Whereas on the second problem, a cantilever beam with electromagnetic actuators, with a higher degree of nonlinearity than the previous one, was used and 
the numerical experiments showed that the displacement convergence was the same for all methods. However, the temporal convergence of these methods were different for both the impulsive condition and the impulsive condition plus the periodic condition. Therefore, it was concluded, with this last analysis, that the method with the best temporal convergence for this problem was the Central Difference Method, although not being the fastest method.

Finally, it is believed that a careful computational analysis of the numerical methods used to solve the given problem is necessary, because, depending on it, the solution may need small time steps, physically and numerically wise.

\section{Referências}

ADHIKARI, S. Damping Models for Structural Vibration. Cambridge: Cambridge University, 2000.

BATHE, K. J. Finite Element Procedures. 2. ed. Pearson Education: United States, 2014.

BELHAQ, M.; BICHRI, A.; DER HOGAPIAN, J.; MAHFOUD, J. Effect of electromagnetic actuations on the dynamics of a harmonically excited cantilever beam. International Journal of Non-Linear Mechanics, v. 46, n. 6, p. 828-833, jul. 2011. DOI:

https://doi.org/10.1016/j.ijnonlinmec.2011.03.001.

BORINO, G.; MUSCOLINO, G. Mode-superposition methods in dynamic analysis of classically and non-classically damped linear systems. Earthquake Engineering Structural Dynamics, v. 14, p. 705-717, set./out. 1986. DOI: https://doi.org/10.1002/eqe.4290140503.

CHANG, Shuenn Yih. Studies of newmark method for solving nonlinear systems: (I) Basic analysis. Journal of the Chinese Institute of Engineers, v. 27, n. 5, p. 651-662, 2004. DOI: https://doi.org/10.1080/02533839.2004.9670913.

HUTTON, D. Fundamentals of Finite Element Analysis. 1. ed. United States: The McGraw-Hill Companies, 2004.

KHAN, M. S.; KANEEZ, H. Nonlinear Vibration Analysis of Euler-Bernoulli Beams by Using Continuous Galerkin-Petrov Time-Discretization Method. Latin Americal Journal of Solids and Structures, v. 14, n. 9, p. 1695-1709, set. 2017. DOI:

https://doi.org/10.1590/1679-78253327.

REMANI, C. Numerical Methods for Solving Systems of Nonlinear Equations. Thunder Bay: Lakehead University, 2013.

REZAIEE-PAJAND, M.; KARIMI-RAD, M. An Accurate Predictor-corrector Time Integration Method for Structural Dynamics. International Journal of Steel Structures, v. 17, p. 1033-1047, 30 set. 2017. DOI: https://doi.org/10.1007/s13296-017-9014-9. 
STROGATZ, S. H. Nonlinear Dynamics and Chaos With Applications to Physics, Biology, Chemistry, and Engineering. 2. ed. Boca Raton (US): CRC Press Taylor and Francis Group, 2018.

TOLEDO, R. C. P. L. Um estudo sobre métodos de integração direta para a análise dinâmica não-linear de estruturas. Orientador: Nelson Francisco Favilla Ebecken. 96 p. 1983. Tese (Mestrado em Engenharia Civil) - Programa de Pós-Graduação em Engenharia Civil, Universidade Federal do Rio de Janeiro, Rio de Janeiro, 1983. Disponível em: http://hdl.handle.net/11422/3384. Acesso em: 18 dez. 2020.

TSAI, S. Y. Numerical computation for nonlinear beam problem. National Sun Yat-sen University, Taiwan, jul. 2005. Disponível em: https://etd.lis.nsysu.edu.tw/ETD-db/ ETD-search/getfile?URN=etd-0704105-220532\&filename=etd-0704105-220532.pdf. Acesso em: 18 dez. 2020.

VIEIRA, L. C. L. M. Estudo de algoritmos de integração elemento por elemento para análise dinâmica não linear de estruturas. Orientador: Adeildo Soares Ramos Júnior. 2004. 121 f. Dissertação (Mestrado em Estruturas) - Universidade Federal de Alagoas, Maceió, 2004. Disponível em: http://www.repositorio.ufal.br/handle/riufal/383. Acesso em: 18 dez. 2020.

YUAN, Ya-Xiang. Recent advances in numerical methods for nonlinear equations and nonlinear least squares. Numerical Algebra, Control and Optimization, v. 1, n. 1, p. 15-34, 2011. DOI: http://dx.doi.org/10.3934/naco.2011.1.15. 